\title{
European UNESCO Cultural Heritage sites and the air pollution effects
}

\author{
S. Doytchinov \& A. Screpanti \\ ENEA, Environmental Department, C.R. Casaccia, 00100 Rome, Italy
}

\begin{abstract}
The International Cooperative Program on Effects on Materials, including Historic and Cultural Monuments, is one of the effect oriented ICP-s under the Convention of Long Range Transboundary Air Pollution (CLTAP) of Geneva, which studies the corrosion effects of air pollution on materials.

The Cultural Monuments (CM) created centuries ago that are exposed to the open air are very sensitive to air pollution and some meteo-climatic parameters, which have corroded them over time. Europe has one of the largest concentrations of Cultural Heritage $(\mathrm{CH})$ sites in the world. There are 745 sites included in the UNESCO list, 387 of them in situated in Europe. In our study we separate the European $\mathrm{CH}$ sites from the national parks and the remaining 243 $\mathrm{CH}$ sites were introduced one by one with exact geographical coordinates on the European EMEP (50x50 km grid) projection map. To better represent the concentration of CM in a single UNESCO site, the remaining sites were divided into three categories (single monument, group of three to four monuments and a large group of monuments), which were represented with different symbols on the European map. So it became clear that the majority of $\mathrm{CH}$ sites are concentrated in certain areas in Europe (the Mediterranean and Central European).
\end{abstract}

Using the EMEP data, the European maps of media annual concentrations of the most corrosive air pollutants and the values of the meteo-climatic parameters were elaborated. To better understand the evolution trend of the air pollution concentrations and the meteo-climatic situation three maps were produced for every pollutant (for 1980, 1990 and 2000).

The air pollution and meteo-climatic maps were placed on top of the European map of UNESCO sites mentioned previously. So it became very clear which monuments had been exposed to which specific kinds of air pollution and environmental effects in the last 20 years. In some parts of the continent (the Mediterranean and some Central areas) where a large part of the $\mathrm{CH}$ were exposed during the last 20 years some of the most corrosive air pollutants remained on the same concentration level. Here special attention for the preservation of the European $\mathrm{CH}$ is needed.

Keywords: EMEP transboundary air pollution, corrosion effects, UNESCO European cultural heritage, anthropogenic activity. 


\section{Methodology}

The atmospheric environment has a very negative effect on the different ecosystems, the human health and materials. Different air pollutants have intensive corrosion effect on large types of materials. The Int. Cooperative Program on Effects on Materials, including Historic and Cultural Monuments (ICP materials) is one of the effect oriented ICP-s under the Convention of Long Range Transboundary Air Pollution (CLRTAP) of Geneva. The Program studies the corrosion effects of the air pollutions on materials including the Cultural Monuments. The ICP materials started its studies in 1985. Now the Program is participated from 18 Europeans countries, USA, Canada and Israel with more than 30 exposure stations.

More than 25 years the Convention (CLRTAP-EMEP) study in a very complex way the emissions, diffusion and effects of the air pollution in Europe. On the continental level this studies and results are accepted from the international community and Governments taking part of the Convention (57 countries).

The Cultural Monuments (CM) created centuries ago that are exposed to the open air are very sensitive to air pollution and meteo-climatic factors that may corrode them. For the monuments created centuries ago should be taken into account the accumulated memory effect existing in the materials, their vulnerability and frangibility.

The European $\mathrm{CH}$ is one of the reaches in the world. In our study we used the data elaborated from the International bodies well accepted from the international community. For the European $\mathrm{CH}$ the UNESCO (UN Educational Scientific and Cultural Organization) list of $\mathrm{CH}$ with universal importance was used [1].

In the UNESCO list 745 sites are included, from them 387 are situated in Europe. In our study we separate the European $\mathrm{CH}$ sites from the national parks and reserves and the rest $243 \mathrm{CH}$ sites one by one were introduced with exact geographical coordinates (very often missed in the official list) on the European EMEP (50x50 km grid) projection map. The Arch View program was used for this.

The UNECO sites are very different one from another, starting from a single monument and arriving to sites like "Rome and Vatican city", which after the Italian conservation Authority include more than 2900 monuments. To may better represent the concentration of $\mathrm{CM}$ in a single UNESCO site, the last were divided in 3 categories. The sites from the different groups were represented with different symbols on the European map.

Little ball - single monument from the Selected $\mathrm{CH}$ sites in Europe;

Square- small group of monuments (2-3) of the selected $\mathrm{CH}$ situated in the same place;

Triangle - large group of monuments of the selected $\mathrm{CH}$ situated in the same place (for example: old city of Rome and the Vatican City, old city of Florence etc.). 
So it became clear that a large part of $\mathrm{CH}$ sites are concentrated in certain areas in Europe (Mediterranean and Central European part).

To may valuate the air pollution environment in which the European $\mathrm{CH}$ in the UNESCO list are exposed the official EMEP data was used.

EMEP is the Cooperative Programme for Monitoring and Evaluation of Long Range Transboundary air Pollution of the CLRTAP of Geneva.

EMEP mandate from the Convention is: "To provide sound scientific support for the Convention, in particular in the areas of: - Atmospheric monitoring and modelling, - Emission inventories and emission projections, - Integrated assessment." In our study the EMEP Unified Model official data [2] was used. The model is elaborated on the basis of the official emission inventories data communicated from the Parties of the Convention and continuously tasted from the EMEP monitoring network (around 120 European stations). In our previous studies the air pollutant effect of $\mathrm{SO}_{2}, \mathrm{NO}_{2}, \mathrm{NO}_{3}$ and particulate matters (PM10) on the $\mathrm{CH}$ in Europe was valuated [3].

The following air pollution and meteo-climatic data were used:

$\mathrm{O}_{3}$ - media year concentrations in $\mathrm{ug} / \mathrm{m} 3$ for 1980,1990 and 2000;

$\mathrm{PH}$ - media yearly values for 1980,1990 and 2000;

Water deposits - in mm. total year quantity for 1980, 1990 and 2000;

RH - relative humidity media year values in \% for 1980, 1990 and 2000;

$\mathrm{T}^{\circ} \mathrm{C}$ - media yearly values for 1980,1990 and 2000 ;

One separate map with the yearly media concentrations of ozone and the respective values of meteo-climatic parameters and the distribution of $\mathrm{CH}$ sites in Europe was elaborated for every indicated year. In this article for space reasons only part of the maps are present. To have more resent information, the maps of year 2000 were reported. This is the last official EMEP data available. The use of EMEP databases for different years, permit us to present and valuate the exposure of everyone of UNESCO $\mathrm{CH}$ sites during the last 20 years in Europe in the respective concentrations of the studied air pollutants and the values of meteo-climatic parameters. In this way it became possible to confront the environmental and meteo-climatic situation during the time and valuate the trend environmental evolution around the single sites.

\section{Discussion}

From our previous studies [3] became clear that the distribution of the UNESCO $\mathrm{CH}$ monuments in Europe is not uniform:

- A large number of Europe's UNESCO CH Monuments are concentrated in some Mediterranean and Central European's countries:

- indicated with triangle: there are 63 in total, 40 in the Mediterranean , 14 in Italy;

- indicated with square: there are 43 in total, 22 in the Mediterranean;

- indicated with little ball: are quite uniformly distributed.

As a consequence of the higher concentrations of $\mathrm{CH}$ monuments in Mediterranean and some Central European countries more attention for their preservation is need in this part of the Continent. 
From the elaborated maps we may observe that:

1- The correlation between the ozone concentrations in the continent (EMEP data) and the distribution of the UNESCO $\mathrm{CH}$ monuments in Europe during the last 20 years: $1980-1990-2000$ indicated that in this period it's concentration increase in whole continent. This is valid not only for the Mediterranean area, especially in Italy, Spain and France but in a large part of the Central Europe (Germany, Poland, and Czech Republic) and the UK. The problem covers a very large part of the continent. Considering the high concentration of $\mathrm{CH}$ in the indicated countries, the very negative oxidant effect of ozone of some type of materials may became dangerous for the monuments.

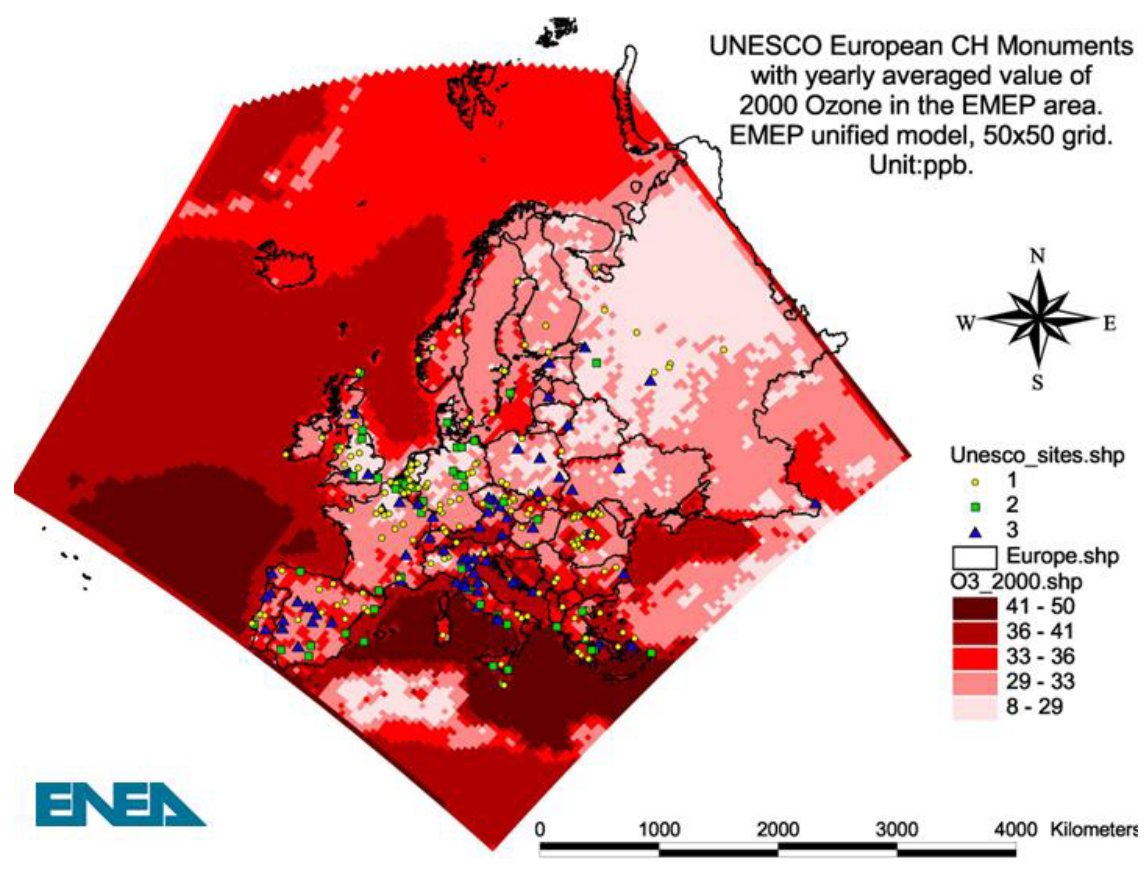

Figure 1: UNESCO European $\mathrm{CH}$ Monuments with yearly averaged value of 2000 Ozone in the EMEP area.

2- The correlation between the meteo-climatic situation in the continent (EMEP data) and the distribution of the UNESCO $\mathrm{CH}$ monuments in Europe during the last 20 years: $1980-1990-2000$ indicated that:

a) The pH media values of the water deposits in Europe changed during the last 20 years. The $\mathrm{pH}$ is a direct indicator of the acidity $\left(\mathrm{H}^{+}\right)$in the precipitations. In this period the $\mathrm{pH}$ increase (the precipitations became more neutral) in large part of Central Europe (Germany, Poland), Scandinavia and the UK with notable benefits for the $\mathrm{CH}$ sites. The $\mathrm{pH}$ values in Italy, Ukraine, Russia and some other central European countries reduced (the water deposits became more acidic), with negative consequences for the $\mathrm{CH}$ exposed on the open air. 
The high oxidant environment is very dangerous for different monuments because this may lead to physical and chemical processes and reactions that are detrimental to the materials and which implement the corrosion effects.

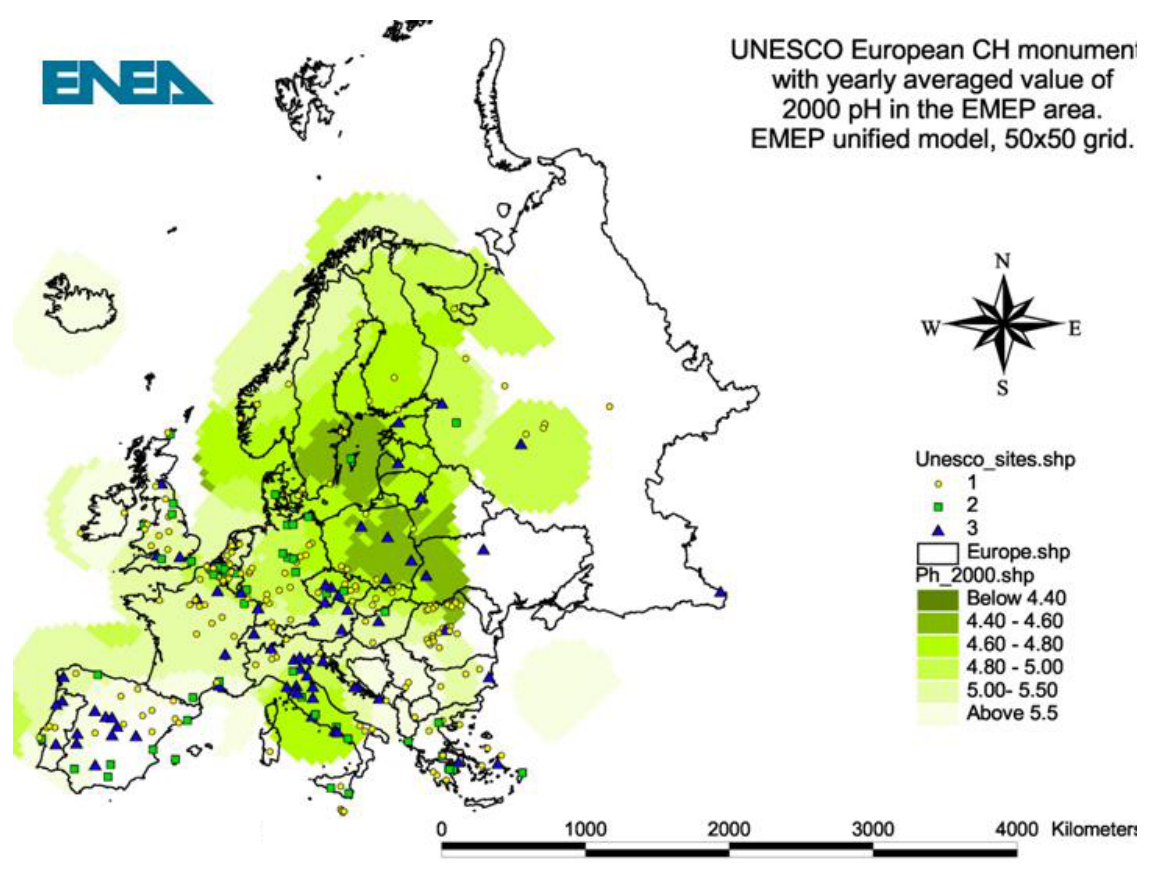

Figure 2: UNESCO European $\mathrm{CH}$ Monuments with yearly averaged value of $2000 \mathrm{pH}$ in the EMEP area.

b) The total precipitation quantity in $\mathbf{m m}$ in Europe in this period changed in different parts of the continent. In the last 20 years in Mediterranean area, Russia, Ukraine and part of Central Europe, precipitation has diminished. The situation has not changed in Scandinavia, the UK and along the west coast of the continent.

The water deposits have different effects on different $\mathrm{CH}$ sites. One is the washing effect on materials (which in most cases is positive) caused by the precipitation washing the deposited pollutants from the surface. Another effect is that the rainwater may dissolve part of the materials from which the object is made. The rainwater may penetrate into the structure of the monuments and when frozen may create cracks into the internal structure.

c) The media yearly values of the Relative Humidity RH (in \%) in this period increase in Scandinavia and along the west coast of the continent. In Central and Eastern Europe the RH diminished and in the Mediterranean area the situation remained stable. This indicates that the $\mathrm{RH}$ is important for the corrosion effect in large areas of our continent with consequences for the $\mathrm{CH}$ exposed there.

The RH is important for the corrosion processes because many chemical reactions may exist only in a humid environment when the $\mathrm{RH}$ is high. When the 
$\mathrm{RH}$ is higher then $80 \%$ and the temperature is around zero degrees it is considered that the surface of the object is humid.
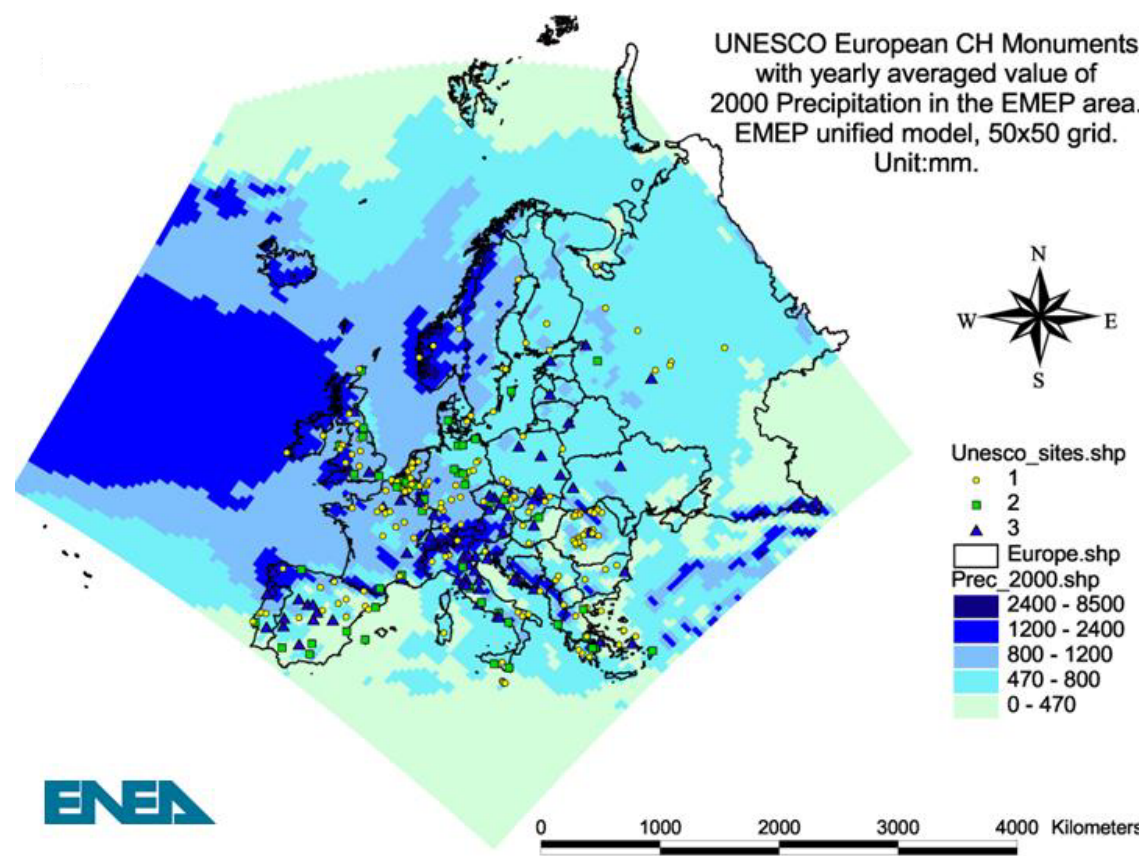

Figure 3: UNESCO European $\mathrm{CH}$ Monuments with yearly averaged value of 2000 Precipitation in the EMEP area.

d) The media year temperature $\left(\mathbf{T}^{\circ}\right)$ during these 20 years has increased over a large part of the continent, especially in south of Scandinavia, Central Europe and Mediterranean area. Considering that the temperature is one of the main factors that may influenced some oxidising chemical reactions in the atmosphere, the temperature trend is very important for the $\mathrm{CH}$ sites exposed to the open air.

In this study we evaluated the European $\mathrm{CH}$ sites in UNESCO list and their exposure during the last 20 years on the transboundary air pollutants and meteoclimatic factors on the continent.

As many $\mathrm{CH}$ monuments are situated in Mediterranean area and Central Europe, to may better understand the corrosion effects of the air pollution on them we will need to develop a regional studies and valuations of effects of the air pollution in these areas.

Many $\mathrm{CH}$ monuments are situated in the cities. There they are exposed to the urban air pollutants. This means that we need an evaluation and application of urban air pollution models in some different kinds of cities in which a large number of CM are presented: London, Rome, Paris, Florence, Prague etc.

The Cultural monuments are created during the years using different materials. Any material may have a different response in front of the corrosion effect produced from the air pollution and the meteo-climatic factors. This means 
that it is important to elaborate a methodology for the qualitative and quantitative valuation of the type of materials used for the creation of a large part of $\mathrm{CH}$ monuments exposed in the open air in different parts of Europe. Here we will need to adapt different regional and continental approaches. It will be important to valuate the possibilities for using some indicators to achieve this.

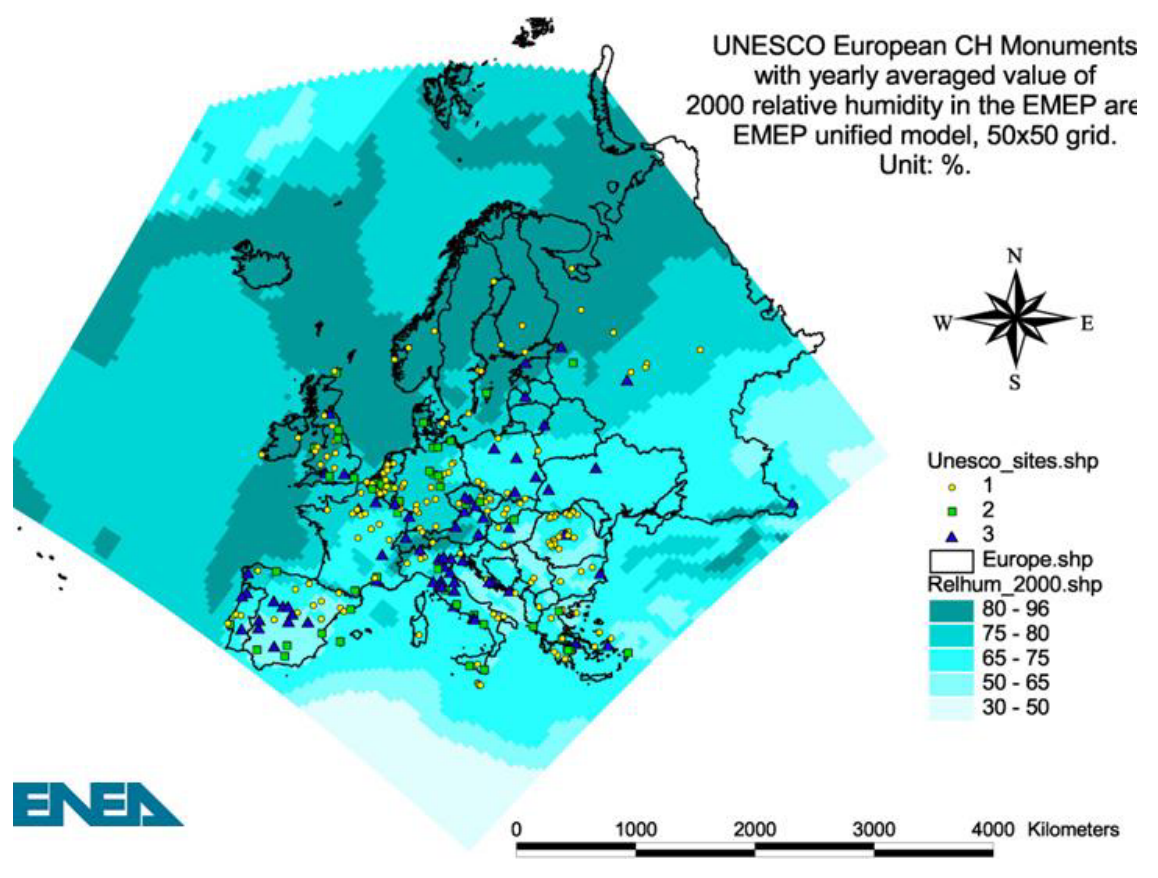

Figure 4: UNESCO European $\mathrm{CH}$ Monuments with yearly averaged value of 2000 relative humidity in the EMEP area.

The situation is more complex in cases like Rome, Paris, Prague, London, Florence or other cities with a very large number of monuments concentrated in the same place.

We believe that some important "Hot spots" situations should be studied. These are locations where there is a large quantity of $\mathrm{CH}$ sites and high concentrations of corrosive air pollutants in the same area.

UNESCO list is very important and fundamental but not always is sufficient. For example, in Italy there are 36 official UNESCO sites: 6 are natural parks, 30 are monuments from which 16 are indicated as "old city of...", 7 are indicated as 2-3 monuments concentrated in the same place and 9 are single monuments.

The "Map of Risk of Italian $\mathrm{CH}$ " elaborated from the Italian conservative Authority up to the present date include more than 48.000 single monuments exposed on the open air [4]. It will be impossible to adapt the Italian map to the continental level, but we will need some other criteria to better represent the important European $\mathrm{CH}$ sites on the continental level. 
This means that we need to individuate a good equilibrium between the previously mentioned extreme cases and of a methodology for the evaluation of the right level of details in which we may arrive in our studies, evaluating the corrosive effect of air pollution on $\mathrm{CH}$ sites in Europe.

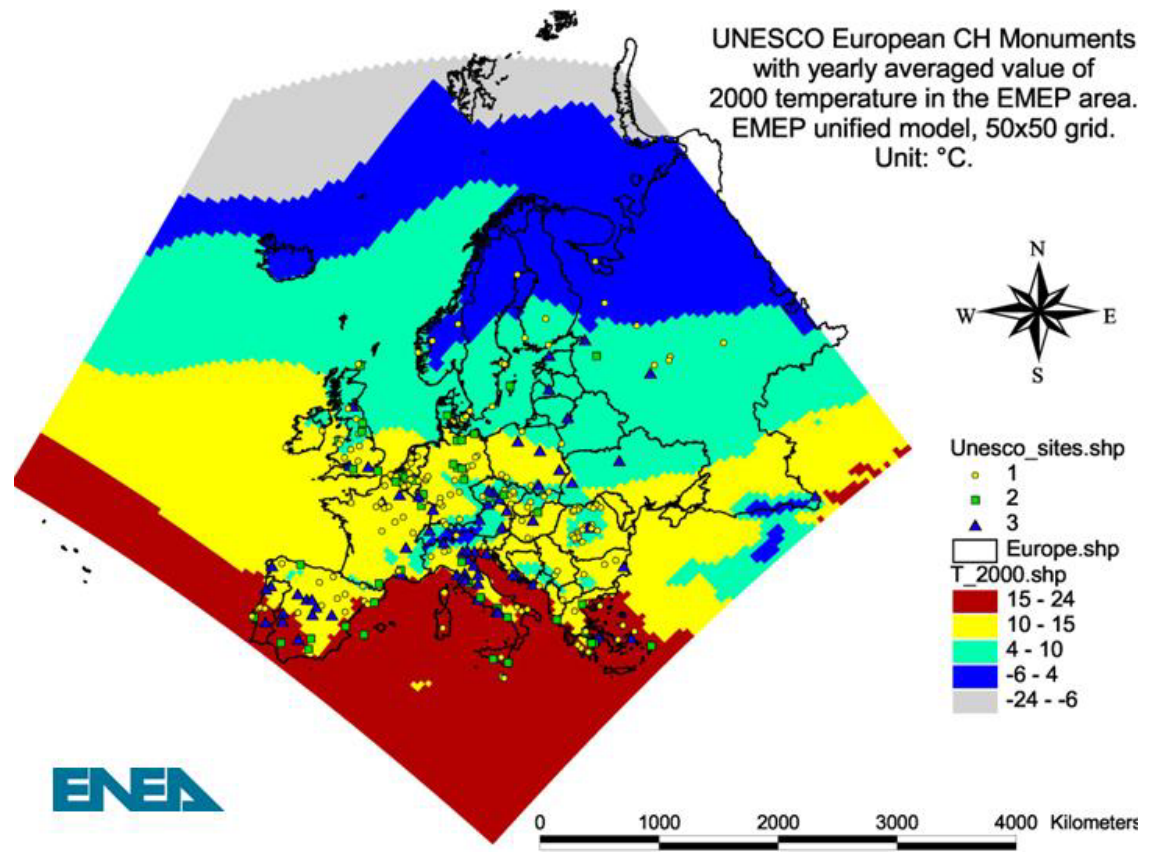

Figure 5: UNESCO European $\mathrm{CH}$ monuments with yearly averaged value of 2000 temperature in ${ }^{\circ} \mathrm{C}$ in the EMEP area.

\section{Conclusions}

1. The geographical and topographical distribution of Europe's UNESCO CH monuments on the continental map was elaborated.

The $\mathrm{CH}$ monuments were divided in three classes after the number of the single monuments presented in the same place.

2. An important part of the Europe's UNESCO CH monuments are concentrated in Mediterranean area and some Central European Countries. Here the corrosion effect of the air pollution and the meteo-climatic factors on the materials used in the creation of $\mathrm{CH}$ monuments should be studied more carefully.

3 . In the last 20 years $1980-1990-2000$ the air pollution and meteo-climatic situation in Europe changed:

A - the media ozone concentration in this period increased in very large part of the continent, especially in the Mediterranean area. This means that the corrosion effects on $\mathrm{CH}$ sites due to the oxidising ozone reactions became higher. 
$\mathrm{B}$ - the media $\mathrm{pH}$ values indicate that in this period the water deposits in Central Europe became more $\mathrm{pH}$ neutral, while in eastern part of the continent and in Mediterranean area they became more acidic. The corrosion effect on the $\mathrm{CH}$ sites due to the water deposits became higher in the last two parts of the continent.

$\mathrm{C}$ - the total year precipitations in the studied period are diminished in large part of Eastern and Central Europe and increased in Scandinavia and along the west coast of the continent, with consequences for the $\mathrm{CH}$.

$\mathrm{D}$ - the media $\mathrm{RH}$ in this period increased in Scandinavia and along the west coast of the continent. In Central Europe they diminished while in the Mediterranean area they remained stable. This may have negative effect on the $\mathrm{CH}$ exposed on the open air in the first two parts of the continent.

$\mathrm{E}$ - the media year temperatures values increased in whole continent, especially in south of Scandinavia, Central Europe and the Mediterranean area. In the areas in which the $\mathrm{T}^{\circ}$ is higher some of the factors determining the corrosion effect increased.

5. In our study in the elaboration of the maps we used only official information accepted from the international community.

a. the $\mathrm{CH}$ monuments are taken from the official UNESCO list of $\mathrm{CH}$ with universal importance;

b. the European environmental data and meteo-climatic factors are the official EMEP data published in the last 25 years with a grid of $50 \times 50 \mathrm{~km}$.

\section{Acknowledgement}

The authors are very grateful of the MSC-West of UN ECE-EMEP for the possibility to utilise the ozone and metheoclimatic data.

\section{References}

[1] UNESCO official list of European $\mathrm{CH}$ with universal importance (2004), www.unesco.org.

[2] EMEP reports for annual concentration data for major air pollutants and meto-climatic factors for 1980, 1990, 2000: www.emep.int.

[3] Doytchinov S., Screpanti A., "Study of the air pollution effect on UNESCO Cultural Heritage sites with universal importance in Europe", Acts of the Workshop "Cultural Heritage in the City of Tomorrow. Developing Policies to Manage the Continuing Risks from Air Pollution" June 10-12. 2204, London, United Kingdom.

[4] Map of Risk of Italian Cultural Heritage. www.icr.it. 